\title{
A Research Study to Gather the Functional Requirements for a SOA Middleware Application to Bridge the LMS to LOR Data Movement Interoperability Gap for Education
}

\author{
Robert T. Mason \\ Regis University \\ Denver, CO, USA
}

rmason@regis.edu

\author{
Timothy J. Ellis \\ Nova Southeastern University \\ Ft. Lauderdale, FL, USA \\ ellist@nsu.nova.edu
}

\begin{abstract}
This study gathered functional requirements for a Service Oriented Architecture (SOA) Middleware Application that can resolve the data movement interoperability gap that exists between learning management systems (LMS) and learning object repositories (LOR). A panel of Computer Information Systems (CIS) experts participated in a five-stage, web-based, anonymous Delphi process to establish a valid set of criteria for the proposed middleware application. In the process, the panel approved and ranked 28 functional requirements for the proposed application. The functional requirements gathered from this study are being used to build an application prototype using SOA Web Services to move learning object data across the Internet from a LMS to a LOR.
\end{abstract}

Keywords: Service Oriented Architecture (SOA), Learning Object Repository (LOR), Learning Management System (LMS), Learning Object (LO), Delphi Technique

\section{Introduction}

Broisin, Vidal, Meire, and Duval (2005) identified the interoperability gap that exists between Learning Management Systems (LMS) and Learning Object Repositories (LOR). Briosin et al. (2005, p. 478) aptly observed, "It is clear that some sort of interface between the two components (LMS \& LOR) is required to enable a system to benefit from the other one." , LMSs are independent computer systems that manage and deliver course content to students via a web interface. In contrast, LOR functionality includes storage, cataloging of metadata, inquiry, and retrieval of Learning Objects (LOs) for design, maintenance and reuse. Therefore, the purpose and functionality of LMS software in comparison to LOR software is very different. LMSs and LORs exist

Material published as part of this publication, either on-line or in print, is copyrighted by the Informing Science Institute. Permission to make digital or paper copy of part or all of these works for personal or classroom use is granted without fee provided that the copies are not made or distributed for profit or commercial advantage AND that copies 1) bear this notice in full and 2) give the full citation on the first page. It is permissible to abstract these works so long as credit is given. To copy in all other cases or to republish or to post on a server or to redistribute to lists requires specific permission and payment of a fee. Contact Publisher@InformingScience.org to request redistribution permission. on public and private networks located in many different countries. These disparate, independent networks are often only connected via the Internet and leverage a variety of different software and hardware technologies. Therefore, the research objective for this study was to gain a consensus of CIS experts regarding the functional requirements for a new middleware application that would 
resolve the interoperability gap between LMSs and LORs.

Prior research by Krishnamurthy (2006), Sartipi and Dehmoobad (2008), and IMS (2009) suggested that SOA is a sound architecture to resolve the data movement interoperability gap that exists between LMSs and LORs. Mason and Ellis (2010) argued that SOA was the best alternative for a middleware architecture because it provided: (a) loose coupling via message only communication that is conducted at the inter-organizational level, (b) the strongest adaptability and modifiability of the six middleware alternatives that they reviewed, and (c) open standards that support interoperability. Therefore, SOA was the premise for the research study that is described in the next section.

\section{Establishing Functional Requirements}

A hundred and fifty email invitations for a research study to gather the functional requirements for a data movement middleware application to resolve the interoperability gap between LMSs and LORs were distributed to CIS experts during January, 2010. The list of prospects was compiled via the review of peer-reviewed publications from the InSITE 2007, 2008 and 2009 Conference Proceedings. In addition, the invitation to participate in the study was posted on several SOA User Group sites in an attempt to find CIS experts that had knowledge about the topic of data movement between LMSs and LORs. Only eight CIS experts volunteered to participate in the study. One expert volunteer decided at a later time not to participate in the study because his knowledge in this particular area was minimal, thus the expert panel consisted of seven participants.

Dalkey $(1969$, p. 7) demonstrated how group size effects the mean accuracy of a group response for a large set of experimentally derived answers to factual questions. The group error was measured on the logarithmic scale from different group sizes where the researchers knew the answers to the questions and the participants were not given the answers. In precise terms, the group error was calculated as the absolute value of the natural logarithm of the group median divided by the true answer. According to Dalkey, the average group error is high for groups that range in size between one and five participants. He found an average group error of 1.2 for one participant and an average group error of 0.7 for five participants. The average group error rate was near 0.6 for seven participants and therefore this error rate was considered acceptable for this research study.

Study volunteers were asked to review IRB information, answer specific questions about their knowledge and experience in this subject area, and then provide minimal demographic data. The information gathered from the volunteers was reviewed in the context of the study criteria that was predefined for the research. Five of the CIS experts resided in the continental United States and two experts were from Spain and Egypt. As required by the research study guidelines, there was no compensation given to the experts for their participation in this study. The expert qualifications are summarized in Table 1.

The Delphi technique was leveraged for this research study. All the information about the experts was kept confidential and only the researchers knew the identity of the participants. A group with diverse knowledge and skills will almost always make a better decision than an individual according to Surowiecki (2004). Another key component for good decision making is independent thought that is not heavily influenced by others. Surowiecki provided examples and explained why the group decision making process that is used with anonymous participants is more effective than decisions made by individuals. Because the experts were distributed geographically, the study was conducted using email and a web-based survey application. The survey tool offered excellent security, supported a variety of question formats (e.g. open questions and Likert scale questions), and allowed the researchers to include graphics in each survey. 
Table 1. A List of Expert Qualifications for this study

Qualification Description

\begin{tabular}{ll}
\hline Education & Four experts had M.S. Degrees in CIS related fields, such as Computer Sci- \\
& ence, Management Information Systems, Information Systems, and Compu- \\
& tational Science. Three of the experts had completed multiple M.S. Degrees \\
& in CIS related fields.
\end{tabular}

Three experts had a Ph.D. in Education Technology, Computer Science \& Technology, and Communications \& Computing.

Employment Four experts were employed by Universities and/or Research Institutions at the time of this research.

Three experts were employed in the private sector by large corporations.

Publications Five of the experts published a total of 42 peer-reviewed publications in the areas of LOs, LORs and/or LMSs.

Experience Six of the experts had design and development experience in the area of Service Oriented Architecture. Three of the experts had used SOA specifically with LMSs and/or LORs.

The seven experts had a total of 37 years of experience working with LOs, LORs, LMSs and/or Learning Object Metadata.

\section{Survey One}

The first survey was designed to solicit ideas (e.g. a brainstorming exercise) for functional requirements that could later be discussed and refined by the expert panel. The question format was open (shown in Figure 1), allowing free form entry by the experts. All of the participants responded to the first survey by February, 2010. The group results for the first survey generated a list of 40 functional requirements. Thirteen of the functional requirements were specific to a LOR or LMS, therefore the researchers decided that these requirements would not be included in the research study as it progressed to subsequent rounds. The focus of the study was to gather functional requirements for a new middleware application that would reside between a LMS and LOR. Therefore, the requirements for non-middleware applications (e.g. specific to a LMS and LOR) were not considered relevant to this research study. The list of functional requirements was compiled and then distributed to the expert panel for review as part of the next survey.

Please list and describe the functional requirements that you consider necessary for a new Internet-based distributed middleware application that can extract and move data from a LMS to a LOR across the Internet using SOA. Also, please include constraints for the functional requirements. For example, you may identify a requirement for automated email notification when new student assessment LOM has been added to a LOR. A constraint for this requirement might be that the email notification will be sent to a specific group of people such as LO designers and/or authors. Please try to be as specific as possible when defining the functional requirements.

Figure 1. The open-ended question from the first survey 


\section{Survey Two}

The second survey was distributed to the CIS expert panel in February, 2010 and was completed by the expert panel in March, 2010. The format for the second round of questions was changed to a five-point Likert scale to allow analysis of the results using statistical methods. The CIS experts were asked to evaluate each of the 27 functional requirements that were generated from the first survey by selecting one of five choices: Strongly Disagree, Disagree, Undecided, Agree, Strongly Agree. Each question was also followed by an open-ended question that allowed the experts to explain their decisions, amend the question, and add any other comment that they felt were relevant. At the end of the survey, a general comment area was provided for the participants to document overall comments about the survey process. Figure 2 shows an example of a Likert Scale question based on one functional requirement suggested by the panel of experts. The first question is followed by an open-ended question to allow expert comments and ideas for revising the first question.

1) The middleware should provide the capability to extract individual course components from the LMS as well as the capability to extract the entire course.

Strongly Disagree
Disagree
Undecided
Agree
Strongly Agree

2) Please use this area to amend a requirement, enter a new requirement or enter a comment about the functional requirement from the prior question.

\section{Figure 2. A sample Likert scale question followed by an open-ended question from survey two.}

The Round Two survey resulted in approval for 17 of the proposed functional requirements. Requirements that had a majority of agree or strongly agree responses, had two or fewer undecided responses, and did not have any disagree or strongly disagree responses were considered approved. The remaining 10 functional requirements had a mixture of responses that included agree, undecided, and disagree. Comments suggested that two of the undecided requirements should be split into separate requirements to enhance the clarity of the requirements. Therefore, for survey three, the researchers separated two of the requirements into two parts each. The net result was an increase of the undecided requirements from 10 to 12 .

The 12 undecided requirements continued into the third survey using the same Likert scale question format used in the second survey (Figure 2). The consolidated group results from survey two with expert comments were returned to the expert participants for review. In addition to the Likert scale responses (Strongly Agree, Agree, etc.) for the third survey, the experts provided additional comments for many of the undecided questions. Figure 3 is a sample list of expert comments from the third survey results in regards to a specific requirement for global payment methods. 
I don't consider it (Global Payment) as a requirement but just as an additional feature.

Providing Global Payment methods should be provided by the middleware if payment processing is a functional requirement. Profit reporting could be a requirement but is not dependent on providing payment methods.

I repeat my earlier statement that the ideology behind repositories is the free sharing of intellectual content.

Please note that there are several global payment solutions like Nelnet, Touchnet, etc. So at the minimum, middleware should be able to integrate with other payment gateways. This is even more important because of the tight restrictions on PCI compliance for gateway providers.

Figure 3. A sample of expert comments for one particular requirement

\section{Survey Three}

The third survey began in March, 2010 and was completed by May, 2010. The duration of the survey was extended to meet the needs expressed by several of the participants. To verify expert approval, the 17 functional requirements approved in survey two were finalized via the first question of survey three in which experts were asked specifically to list any approved requirements that needed further discussion. All of the seventeen approved requirements were finalized by the experts.

After completion of the third survey by all of the experts, one of the undecided requirements that had one disagreement response from the second survey was changed to an agreement response. Therefore, this requirement was added to the approved list bringing the total of approved requirements to 18 at the conclusion of the third round. The third survey response data provided two rounds of quantitative data from the Likert Scale question format. Thus, it was possible to test all the undecided questions for convergence and stability.

\section{Statistical Analysis for Stability and Convergence}

As mentioned earlier, this research study used the Delphi method that is an effective research process to gain the consensus of a panel of experts (Delbecq, Ven de Ven, \& Gustafson, 1975; Linstone \& Turloff, 2002; Skulmoski, Hartman, \& Krahn, 2007; Simon et al., 2008). The Delphi method has been used in the support of a wide range of quantitative and qualitative research studies (Skulmoski et al., 2007). The Delphi method is an iterative process used to collect and analyze expert judgment using a series of surveys as was demonstrated in this research study.

Holey, Feeley, Dixon and Whittaker (2007) discovered that there was no general agreement in the literature that defines the specific criteria to determine when to stop a research study using the Delphi method. Holey et al. noted that within the literature, expert consensus or agreement was attained by: (a) the aggregation of a pool of participant judgments, (b) a movement towards a central tendency, or (c) confirming stability based on subsequent Delphi rounds. The Holey et al. research compared various statistical approaches to determining stability and convergence in Healthcare research studies that used the Delphi method. Stability was defined by Turoff and Linstone (2002) as the distribution of the group's response along the interval scale over successive rounds. Turoff et al. suggested that the stability approach was a significant measure for developing a stopping criterion to indicate group consensus. For this research study, a holistic ap- 
proach was taken and the response data was evaluated using several different statistics to determine stability and convergence as described below:

1. Two Simple Central Tendency statistics, such as changes of the Mean (Average) and Standard Deviation across study rounds that were $15 \%$ or less indicated stability and convergence (Franchak, Desy, \& Norton, 1984; Scheibe, Skutsch, \& Schofer, 1975).

2. A decrease (or the same value) in the Standard Deviation across rounds indicated stability (Franchak et al., 1984).

3. A Coefficient of Variation (CV) of less than .5 indicated convergence (Dajani, Sincoff, and Talley, 1979; English \& Kernan, 1976).

4. Using Pearson's correlation, a value near 1.0 indicated stability (Yang, 2008).

After the experts completed each survey, point values were assigned to each Likert question response using the following scale:

- Strongly Agree $=5$ points

- $\quad$ Agree $=4$ points

- $\quad$ Undecided $=3$ points

- $\quad$ Disagree $=2$ points

- Strongly Disagree $=1$ point

The point values were then used for statistical analysis of the data across the second and third surveys. Based on the analysis, six of the undecided requirements demonstrated indications of stability and convergence. For example, a requirement that reached stability and convergence across the second and third surveys was:

"Data must be transferred for each student session in the LMS."

Table 2 contains the results of a Likert scale question and actual weighted responses. The column headings underneath the table section labeled Results equate to the five possible choices for the Likert scale question from both the second ( $2^{\text {nd }}$ row label on left) and third ( $3^{\text {rd }}$ row label on left) surveys. For example, $\mathrm{SA}=$ Strongly Agree, $\mathrm{A}=$ Agree, $\mathrm{U}=$ Undecided, $\mathrm{D}=$ Disagree and $\mathrm{SD}=$ Strongly Disagree, are shown as column headings under the Results heading. The section labeled Actual Weighted contains a weight value for each expert response. In this example, one expert strongly agreed with the requirement during the $2^{\text {nd }}$ and $3^{\text {rd }}$ survey, therefore five points was shown under the Participant 1 (P1) column heading for both surveys. The Participant 2 (P2) heading shows two values of 4 points in both the $2^{\text {nd }}$ and $3^{\text {rd }}$ rows of the survey results which equates to an agree response. The columns on the right side of table 2 show the calculated values for the mean (average), standard deviation (Std Dev) and coefficient of variation (CV) for the weighted results. The $\mathrm{CV}$ is a normalized measure of dispersion of a probability distribution and was calculated as the ratio of the standard deviation $\sigma$ divided by the mean $\mu$. The rows shown in blue on the second half of the table show the changes of values across the $2^{\text {nd }}$ and $3^{\text {rd }}$ surveys. For example, the mean value across the two surveys remained the same at 3.143 , therefore the value of the mean change is $0 \%$.

Therefore, in the context of the evaluation criteria that was described above by various researchers, Table 2 shows the following data. A mean change of $0 \%$ and a standard deviation change of $14.5 \%$ across rounds indicated stability according to the guidelines suggested by Scheibe, Skutsch, \& Schofer (1975) and Franchak, Desy, \& Norton (1984). The decrease in the standard deviation from 1.574 to 1.345 also indicated stability based on guidelines suggested by Franchak, et al. The Coefficient of Variation (CV) of .428 that for the $3^{\text {rd }}$ survey was less than .5 indicated convergence according the guidelines established by Dajani, Sincoff, and Talley (1979) and Eng- 
lish \& Kernan (1976). A Pearson Correlation of .934 that was near 1.0 indicated stability across the Delphi rounds, according to the guidelines established by Yang (2008).

Table 2. An example of a requirement with stability and convergence

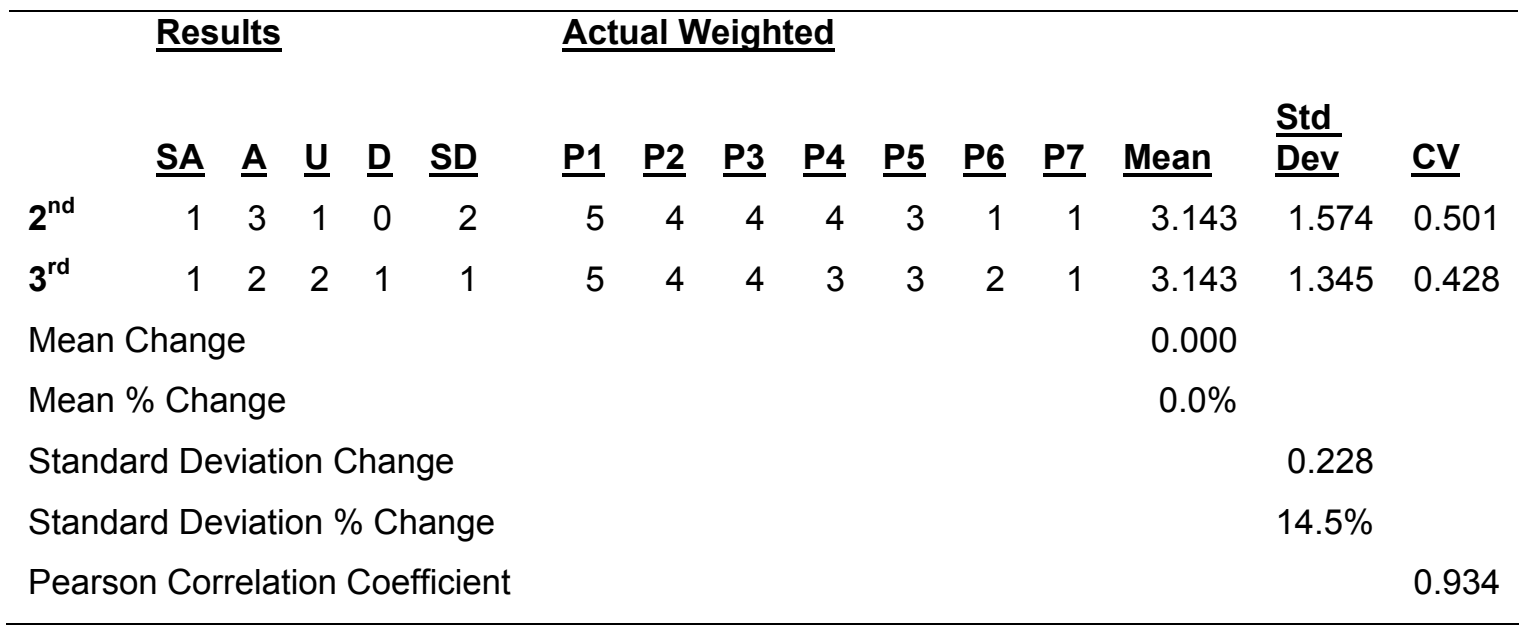

When the statistical analysis for a question showed indicators of stability and convergence, the format of the question was changed. The experts were asked to vote for the requirement by indicating if it should be retained, rejected or reworded. If an expert chose to reword a requirement, then he or she was asked to provide an example of the requirement in a revised format. The reworded option was included because several experts suggested that the wording of certain requirements was vague and therefore needed improvement. Offering the reworded alternative for the fourth survey turned out to be a good approach. Two of the questions from the fourth survey were reworded by the experts to be less ambiguous. The reworded questions were later resubmitted to the experts in the fifth survey for a final vote of reject or retain; in this example, both questions were retained.

\section{Survey Four}

The fourth survey was distributed to the panel of experts on May, 2010 and was completed by June, 2010. One of the approved requirements from the third survey was finalized via the first question in the fourth survey, thus making a total of 18 finalized requirements. As mentioned previously, the question format for the six requirements that indicated stability and convergence was changed to ask the experts if the requirement should be retained, rejected or reworded. After the experts completed the fourth survey, three of the requirements identified as showing stability and convergence were retained and finalized by a majority of the experts. One requirement was rejected by the expert panel on the basis of being ambiguous.

An additional requirement showed mixed indicators of stability and convergence. The mean percent change of $5.0 \%$ indicated stability. However, a standard deviation change of $20.8 \%$ across rounds did not necessarily indicate stability. The increase of the standard deviation from 1.069 to 1.291 did not indicate stability based on the previously identified guidelines. However, the CV of .430 that was less than .5 appeared to indicate convergence and a high Pearson Correlation .966 showed a trend towards stability. Therefore, the researchers decided that the requirement was showing enough indication of stability and convergence across the third and fourth surveys to allow a vote. This requirement was submitted during the fifth survey and the experts were asked to retain or reject it. 
Four of the requirements in Likert Scale format from the fourth survey were moved to the approved list because all of the responses changed to either agree or strongly agree with only one expert response that was undecided. During the fifth and final survey, experts were asked to finalize these four approved requirements from the fourth survey. The results and comments from the fourth survey were aggregated and then returned to expert panel for review.

\section{Survey Five}

The fifth survey was distributed in June, 2010 and was completed by July, 2010. As mentioned above, the fifth survey began by asking the experts to finalize the four approved requirements from the fourth survey, which they did. The next three survey questions asked the experts to either retain or reject three of the requirements. One of the three requirements had reached stability as described in the prior section of this paper and the other two requirements were reworded by the experts as a result of the fourth survey.

The last section of the fifth survey asked the experts to indicate if the following requirement(s) were essential/critical to the middleware application. The five choices for the question were as follows: (a) Strongly Agree, (b) Agree, (c) Undecided, (d) Disagree, and (e) Strongly Disagree. Point values were assigned to each Likert question response using the following scale:

- Strongly Agree $=5$ points

- $\quad$ Agree $=4$ points

- Undecided $=3$ points

- $\quad$ Disagree $=2$ points

- Strongly Disagree $=1$ point

The weighted points were tallied for each requirement. The requirements were then sorted in order with the highest point values at the top of the list and lower point values at the bottom of the list. The three remaining undecided requirements were included in the ranking list with the understanding that they would be removed from the list if a majority of the experts voted to reject the requirements at the conclusion of the fifth survey. By including the undecided requirements in the ranking process, the researcher was able to avoid an additional survey. The remaining three requirements were in fact retained by the CIS experts after the fifth survey was completed. Table 3 contains a summary of the 28 approved, finalized and ranked functional requirements.

Table 3. Ranked Middleware Application Functional Requirements

\begin{tabular}{|c|c|c|c|c|c|c|}
\hline $\begin{array}{l}\text { Ranked, Approved and Finalized Functional } \\
\text { Requirement }\end{array}$ & $\begin{array}{l}\frac{\text { Total }}{\text { Ranking }} \\
\underline{\text { Points }}\end{array}$ & $\underline{\mathrm{SA}}$ & $\underline{\mathrm{A}}$ & $\underline{\mathrm{U}}$ & DA & $\underline{\mathrm{SDA}}$ \\
\hline $\begin{array}{l}\text { The middleware should provide Events monitor- } \\
\text { ing. For instance, a new student assessment LOM } \\
\text { has been added to a LOR so that actions and us- } \\
\text { ers who perform such actions are tracing and reg- } \\
\text { istering. }\end{array}$ & 34 & 6 & 1 & 0 & 0 & 0 \\
\hline $\begin{array}{l}\text { The middleware needs to provide fault tolerance } \\
\text { capability. Fault tolerance (aka graceful degrada- } \\
\text { tion) is the property that enables a computer sys- } \\
\text { tem to continue operating properly in the event of } \\
\text { the failure of (or one or more faults within) some } \\
\text { of its components. }\end{array}$ & 32 & 5 & 1 & 1 & 0 & 0 \\
\hline
\end{tabular}


Ranked, Approved and Finalized Functional $\underline{\text { Requirement }}$

The middleware needs to provide load balance capability. The middleware should offer scalability - a large number of users with little performance degradation.

The middleware should be compatible with different Major LMS Providers (e.g. Moodle, Blackboard, etc.)

The service provided by the middleware is configurable.

The middleware must accommodate the expected termination of student sessions.

The middleware should use ACK messages to confirm the exchange of resources between LMSs and LORs.

The middleware should cipher critical requests, such as storing assessment resources.

The middleware should produce a log that documents all inputs, including re-inputting of amended content already existing in the LOR.

The middleware should provide APIs (application programming interfaces), so that external developers can connect to it and make use of it.

The middleware should have user protected security features. For example, to avoid requests for a resource by a particular user from different physical addresses.

The LMS must transfer data to LOR when LOR becomes available using the middleware. Constraint: LMS must be aware of the LOR state.

The middleware component/service needs to be reusable.

The middleware should offer multiple user definitions, e.g., student, instructor, admin with appropriate permissions. Secure authentication via automatic validation of the user based on his LMS user profile, or Standard Authentication, and Authorization techniques, like Open ID. Security mandatory login credentials Instructor query/sort/filter of assessments.
Total

Ranking

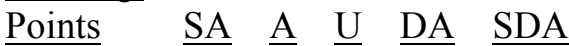

$\begin{array}{llllll}30 & 4 & 2 & 0 & 1 & 0\end{array}$

$\begin{array}{llllll}30 & 3 & 3 & 1 & 0 & 0\end{array}$

$\begin{array}{llllll}30 & 4 & 1 & 2 & 0 & 0\end{array}$

$\begin{array}{llllll}30 & 3 & 3 & 1 & 0 & 0\end{array}$

$\begin{array}{llllll}29 & 2 & 4 & 1 & 0 & 0\end{array}$

$\begin{array}{llllll}29 & 3 & 3 & 0 & 1 & 0\end{array}$

$\begin{array}{llllll}28 & 4 & 1 & 0 & 2 & 0\end{array}$

$\begin{array}{llllll}28 & 4 & 0 & 2 & 1 & 0\end{array}$

$\begin{array}{llllll}28 & 3 & 3 & 0 & 0 & 1\end{array}$

$\begin{array}{llllll}27 & 2 & 2 & 3 & 0 & 0\end{array}$

$\begin{array}{llllll}27 & 3 & 1 & 2 & 1 & 0\end{array}$

$\begin{array}{llllll}27 & 1 & 4 & 2 & 0 & 0\end{array}$ 


\section{$\underline{\text { Ranked, Approved and Finalized Functional }}$ Requirement}

The middleware should provide the capability to extract individual course components from the LMS as well as the capability to extract the entire course.

The middleware needs to provide service design documentation.

The middleware must support Standards such as SCORM, IEEE LOM.

The middleware needs to provide the interface to front-end and back-end applications.

The average response time for the middleware should be within the default/average middleware response times based on technological capabilities and advancements accepted and defined at that time. An SLA needs to be defined to take into consideration whether the process is a batch or real-time or a GUI interface.

The middleware should be capable of tracking and reporting information about group and individual user requests. For example, report on the number of requests for a resource by a particular user. Reporting requirements will be determined later in the design process.

The middleware needs to handle many of the back-end system data extraction requests. The exact number can be determined further along in the design process.

The middleware should provide the ability to rank LOs and store the results in the LOR.

The middleware should provide Intelligent techniques and algorithms to extract data from available LOs.

The middleware should transfer LMS Enrollment data to a LOR in a real-time fashion (seats available, seats empty, wait list, reserved seats)

The middleware should provide Email notification to interested parties when specified events happen. Those interested parties might be educational institutions mainly.

Text data must be transferred for each student session in the LMS.
Total

Ranking

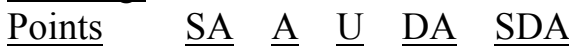

$\begin{array}{llllll}26 & 1 & 5 & 0 & 0 & 1\end{array}$

$\begin{array}{llllll}26 & 2 & 2 & 2 & 1 & 0\end{array}$

$\begin{array}{llllll}25 & 1 & 4 & 1 & 0 & 1\end{array}$

$\begin{array}{llllll}24 & 1 & 3 & 2 & 0 & 1\end{array}$

$\begin{array}{llllll}24 & 1 & 3 & 1 & 2 & 0\end{array}$

$\begin{array}{llllll}23 & 2 & 2 & 1 & 0 & 2\end{array}$

$\begin{array}{llllll}23 & 1 & 1 & 4 & 1 & 0\end{array}$

$\begin{array}{llllll}22 & 0 & 3 & 3 & 0 & 1\end{array}$

$\begin{array}{llllll}21 & 1 & 1 & 3 & 1 & 1\end{array}$

$\begin{array}{llllll}21 & 1 & 1 & 3 & 1 & 1\end{array}$

$\begin{array}{llllll}21 & 1 & 0 & 4 & 2 & 0\end{array}$

$\begin{array}{llllll}21 & 0 & 2 & 4 & 0 & 1\end{array}$ 


\section{$\underline{\text { Ranked, Approved and Finalized Functional }}$ Requirement}

The LMS should push the data to LOR rather than LOR pulling the data from LMS using the middleware application. Constraint: LMS must know where LOR is located.

The middleware should provide Global Payment methods, in case LO owners want to identify their profit from selling an LO.
Total

Ranking Points SA A U DA SDA $\begin{array}{lllll}0 & 2 & 2 & 2 & 1\end{array}$

$\begin{array}{llllll}18 & 1 & 0 & 1 & 5 & 0\end{array}$

\section{Summary}

A panel of CIS experts participated in five web-based anonymous surveys that consisted of open questions, Likert scale questions and final confirmation type questions (e.g. retain or reject). The CIS experts approved, finalized and ranked 28 functional requirements for a SOA Middleware Application that can resolve the data movement interoperability gap that exists between LMSs and LORs. The Delphi technique was leveraged during the study to identify the Likert Scale responses from prior surveys that indicated stability and convergence using statistical analysis. Responses that indicated stability and convergence were put to a final vote in subsequent surveys.

This research provided an important milestone in the ongoing effort to bridge the interoperability gap that exists between LMSs and LORs. The definition of the functional requirements was the first major step that provided tangible CIS expert guidance towards the resolution of the interoperability gap. The functional requirements have been leveraged by the researchers to create design documentation that is serving as the blue print for a new SOA middleware application. The design documentation includes: (a) UML Use Case diagrams, (b) class diagrams, (c) state transition diagrams, (d) an Entity Relationship Diagram (ERD) for the necessary metadata, and (f) a comprehensive detailed design specification. The SOA Middleware prototype that is based on the 28 functional requirements was completed by Spring 2011.

A major goal of this research was to provide a working mechanism for course instructors to store, retrieve, embellish and share LOs (course materials) with their colleagues via a simple and friendly Middleware application interface.

Future research may include the development of the Middleware prototype into a fully operational application for use by many universities. At a minimum, this additional research will require: (a) the design of new Web services to accommodate various LMSs and LORs that were not included in the research prototype, (b) a Usability study of the Web-based interface, and (c) an evaluation of the technology platform to accommodate a high capacity work load.

\section{References}

Broisin, J., Vidal, P., Meire, M., \& Duval, E. (2005). Bridging the gap between learning management systems and learning object repositories: exploiting learning context information. Proceedings of the Advanced Industrial Conference on Telecommunications/Service Assurance with Partial and Intermittent Resources Conferencel E-Learning on Telecommunications Workshop, 478-483.

Dalkey, N. C. (1969). The Delphi Method: An experimental study of group opinion. Retrieved, 2009, from http://www.rand.org/pubs/authors/d/dalkey_norman_crolee.html 
Dajani, J. S., Sincoff, M. Z., \& Talley, W. K. (1979). Stability and agreement criteria for the termination of Delphi studies. In Technological forecasting and social change (Vol. 13, pp. 83-90). Santa Monica, CA: Rand Corporation.

Delbecq, A. L., Van de Ven, A. H., \& Gustafson, D. H. (1975). Group techniques for program planning: A guide to nominal group and Delphi processes. Glenview, IL: Scott, Foresman and Company.

English, J. M., \& Kernan, G. L. (1976). The prediction of air travel and aircraft technology to the Year 2000 using the Delphi method. Transport Research, 10, 1-8.

Franchak, S. J., Desy, J., \& Norton, E. L. (1984). Involving business, industry, and labor: Guidelines for planning and evaluation vocational education programs. In Research and development series. No. 250 (pp. 1-83). The Ohio State University at Columbus: The National Center for Research in Vocational Education.

Holey, E. A., Feeley, J. L., Dixon, J., \& Whittaker, V. J. (2007). An exploration of the use of simple statistics to measure consensus and stability in Delphi studies. In BMC medical research methodology (2007th ed., Vol. 7, pp. 7-52).

IMS Global Learning Consortium, Inc. (2009). Adoption of Service Oriented Architecture (SOA) for enterprise systems in education: Recommended practices. Retrieved August 10, 2009, from http://www.imsglobal.org/community/forum/index.cfm?forumid=10.

Krishnamurthy, L. (2006). Comparative assessment of network-centric software architectures. Masters of Science Thesis, 1-98. Virginia Polytechnic Institute and State University, Blacksburg, Virginia.

Mason, R., \& Ellis, T. (2010). A recommendation for the use of Service Oriented Architecture (SOA) to bridge the LMS to LOR data movement interoperability gap for education. Proceedings of the Informing Science \& IT Education Conference (InSITE) 2010, 43-56.

Sartipi, K., \& Dehmoobad, A. (2008). Cross-domain information and service interoperability. Proceedings of the 10th International Conference on Information Integration and Web-based Applications \& Services, 25-32.

Scheibe, M., Skutsch, M., \& Schofer, J. (1975). Experiments in Delphi methodology. In H. A. Linstone \& M. Turoff (Eds.), The Delphi Method: Techniques and applications (pp. 262-287).

Simon, Carbone, A., de Raadt, M., Lister, R., Hamilton, M., \& Sheard, J. (2008). Classifying computing education papers: Process and results. Fourth International Computing Education Research Workshop (ICER 2008), 161-172.

Skulmoski, G. J., Hartmann, F. T., \& Krahn, J. (2007). The Delphi Method for graduate research. Journal of Information Technology Education, 6, 1-21. Retrieved from http://www.jite.org/documents/Vol6/JITEv6p001-021Skulmoski212.pdf

Surowiecki, J. (2004). The wisdom of crowds: Why the many are smarter than the few and how collective wisdom shapes business, economies, societies and nations. New York: Anchor Books. Retrieved November 25, 2009, from Books24x7: http://common.books24x7.com/book/id_10328/book.asp

Turoff, M., \& Linstone, H. (2002). The Delphi Method: Techniques and applications. Retrieved on October 10, 2010 from http://is.njit.edu/pubs/delphibook/

Yang, Y. N. (2008). Methodology for testing the stability of experts' opinions between successive rounds of Delphi studies [Data file]. Available from: http://www.tw.org/newwaves/63/1-9.html 


\section{Biographies}

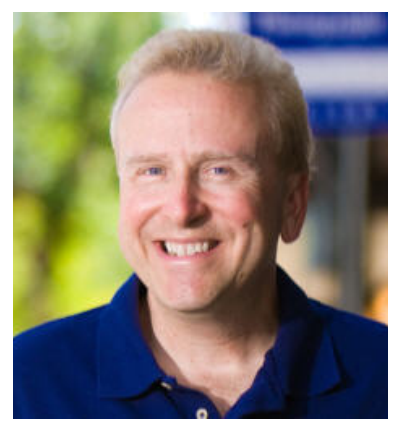

Bob Mason is completing the last 5\% of his Ph.D. dissertation in Computer Information Systems (CIS) at Nova Southeastern University. As part of his research, he built a SOA Middleware prototype that was based on the 28 functional requirements that were provided by the panel of seven CIS experts. This prototype helps to resolve the interoperability gap challenges that exist between Learning Object Repositories \& Learning Management Systems. He has a MBA with an emphasis in CIS from the University of North Texas. Bob has an undergraduate degree in Forestry Management from the University of Tennessee.

Bob joined Regis University as an Assistant Professor in January, 2011 and is the program coordinator for the SCIS Database Technologies program. Prior to joining Regis as a full-time faculty member, he was an affiliate faculty member at Regis University for 10 years. In addition to teaching, Bob was employed by various Fortune 500 companies for 25 years as a DBA and software engineer. His email address is rmason@regis.edu.

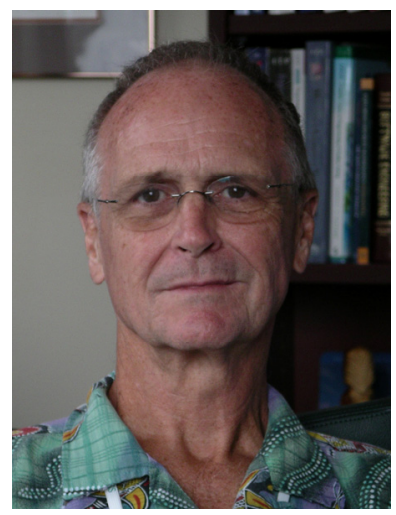

Dr. Timothy Ellis obtained a B.S. degree in History from Bradley University, an M.A. in Rehabilitation Counseling from Southern Illinois University, a C.A.G.S. in Rehabilitation Administration from Northeastern University, and a Ph.D. in Computing Technology in Education from Nova Southeastern University. He joined NSU as Assistant Professor in 1999 and currently teaches computer technology courses at both the Masters and Ph.D. level in the School of Computer and Information Sciences.

Prior to joining NSU, he was on the faculty at Fisher College in the Computer Technology department and, prior to that, was a Systems Engineer for Tandy Business Products. His research interests include: multimedia, distance education, and adult learning. He has published in several technical and educational journals including Catalyst, Journal of Instructional Delivery Systems, and Journal of Instructional Multimedia and Hypermedia. His email address is ellist@nova.edu. His main website is located at http://www.scis.nova.edu/ ellist/ 